Clinical Research Paper

\title{
Anthropometric, clinical and molecular determinants of treatment outcomes in postmenopausal, hormone receptor positive metastatic breast cancer patients treated with fulvestrant: Results from a real word setting
}

\author{
Laura Pizzuti ${ }^{1}$, Clara Natoli ${ }^{2}$, Teresa Gamucci ${ }^{3}$, Mariella Mauri ${ }^{4}$, Domenico Sergi ${ }^{1}$, \\ Luigi Di Lauro ${ }^{1}$, Giancarlo Paoletti ${ }^{1}$, Enzo Ruggeri ${ }^{5}$, Laura Iezzi ${ }^{2}$, Isabella Sperduti ${ }^{6}$, \\ Lucia Mentuccia ${ }^{3}$, Agnese Fabbri ${ }^{5}$, Marcello Maugeri-Saccà ${ }^{1,7}$, Luca Moscetti ${ }^{8}$, \\ Maddalena Barba ${ }^{1,7}$ and Patrizia Vici ${ }^{1}$ \\ ${ }^{1}$ Division of Medical Oncology 2, Regina Elena National Cancer Institute, Rome, Italy \\ 2 Department of Medical,Oral and Biotechnological Sciences, Centro Scienzedell' Invecchiamento e Medicina Traslazionale- \\ CeSI-MeT, Chieti, Italy \\ ${ }^{3}$ Medical Oncology Unit, SS Trinità Hospital, Loc. San Marciano, Sora, Frosinone, Italy \\ ${ }^{4}$ Division of Oncology, San Giovanni Hospital, Rome, Italy \\ ${ }^{5}$ Division of Oncology, Complesso Ospedaliero Belcolle, AUSL Viterbo, Strada S. Martinese, Viterbo, Italy \\ ${ }^{6}$ Biostatistics Unit, Regina Elena National Cancer Institute, Rome, Italy \\ 7 Scientific Direction, Regina Elena National Cancer Institute, Rome, Italy \\ 8 Department of Medical and Surgical Sciences for Children and Adults, Azienda Ospedaliero-Universitaria Policlinico di \\ Modena, Modena, Italy \\ Correspondence to: Maddalena Barba, email: maddalena.barba@gmail.com \\ Keywords: fulvestrant, hormone receptor positive metastatic breast cancer, endocrine sensitivity, endocrine resistance \\ Received: January 10, $2017 \quad$ Accepted: March 15, $2017 \quad$ Published: April 09, 2017
}

Copyright: Pizzuti et al. This is an open-access article distributed under the terms of the Creative Commons Attribution License 3.0 (CC BY 3.0), which permits unrestricted use, distribution, and reproduction in any medium, provided the original author and source are credited.

\section{ABSTRACT}

To characterize determinants of treatment outcome in a real world population of 161 post-menopausal hormone receptor-positive metastatic breast cancer patients treated with fulvestrant. Descriptive statistics for demographics, anthropometrics, clinical and molecular characteristic were compared across subgroups of sensitivity/ resistance to prior endocrine therapy and tested in uni/multivariate models. Clinical benefit was more common in sensitive patients with higher estrogen receptor expression and when fulvestrant was given in first line $(p=0.02$ and 0.046$)$. In resistant patients, PFS was longer with lower BMI $(p=0.01)$. Among endocrine sensitive women, longer PFS was associated with fulvestrant in first-line, single metastasis and no visceral involvement $(p=0.01,0.003$ and 0.01$)$. OS was shorter in resistant patients with HER2-positive disease and if fulvestrant was given in second and subsequent line $(p=0.03)$. In sensitive patients, we observed worse OS with multiple metastases $(p=0.008)$. Multivariate analyses confirmed longer PFS in resistant patients with lower BMI and older age $(p=0.002$ and 0.007$)$. OS in resistant patients was negatively influenced by HER2 positivity and fulvestrant in second and subsequent line $(p=0.04)$. In sensitive women, multiple metastases were associated with poorer survival $(p=0.002)$. This evidence encourages considering patient and disease characteristics in decision making and outcome interpretation for patients candidate to fulvestrant. 


\section{BACKGROUND}

Endocrine therapy has become the mainstay of treatment for hormone receptor positive, human epidermal grown factor receptor 2 negative (HR+HER2-) breast cancer patients and often represents the first among several lines of treatment in metastatic disease. In this setting, the substantial expansion of the available armamentarium has undoubtedly translated into significantly improved outcomes [1].

Fulvestrant acts as a selective ER antagonist, which represses estrogen signaling throughout ER binding, conformational change and consequent block of dimerization followed by ER degradation and downregulation [2-3]. The clinical efficacy of fulvestrant was first shown in two phase III trials of fulvestrant 250 $\mathrm{mg}$ per month versus anastrozole $1 \mathrm{mg}$ daily in $2^{\text {nd }}$ line [4-6]. Subsequently, consistent data in support of a dosedependent effect of fulvestrant [7-9] prompted the design and conduct of the Comparison of Faslodex in Recurrent or Metastatic Breast Cancer (CONFIRM) trial, which showed improved progression-free survival (PFS) and overall survival (OS) in patients treated with a higher dose regimen including a day 14 loading element $(500 \mathrm{mg}$ on days 0,14 , and 28 , and every 28 days thereafter) [10-11]. In the Fulvestrant First-Line Study Comparing Endocrine Treatments (FIRST), a phase II, randomized, open-label, multicenter trial fulvestrant $500-\mathrm{mg}$ was compared with anastrozole in the $1^{\text {st }}$ line setting. A follow-up analysis reported a hazard ratio (HR) of time to progression (TTP) for fulvestrant $500 \mathrm{mg}$ versus anastrozole of 0.66 ( $p$ $=0.01)$ [12]. Results from the overall survival analysis (OS) suggested that fulvestrant $500 \mathrm{mg}$ extended OS compared to anastrozole $(p=0.04)$ [13]. These findings have recently found confirmation in the larger phase III FALCON (Fulvestrant and Anastrozole Compared in Hormonal Therapy Naïve Advanced Breast Cancer) trial (ClinicalTrials.gov identifier: NCT01602380), which has shown significantly longer PFS in the fulvestrant group than in the anastrozole group $(p=0.049)$ [14]. In its current use, fulvestrant is approved in postmenopausal HR+HER2- metastatic breast cancer following progression on previous endocrine treatment at a dose of $500 \mathrm{mg}$ every 4 weeks, after an initial month of biweekly loading dose [15-16].

Endocrine resistance is a complex phenomenon whose roots have been increasingly investigated over the past decade. When addressing resistance to fulvestrant, with the lonely exception of ER, which is a widely accepted indicator of benefit from all endocrine therapies, the predictive role of additional factors have not been clarified yet. In these respects, a valid attempt was made by Graham and coauthors who carried out a systematic review and meta-analysis of 4 RCTs comparing fulvestrant based regimes to aromatase inhibitors (AI) alone. Time to progression/PFS was the primary endpoint. The authors observed longer TTP/PFS in patients treated with fulvestrant in case of visceral metastasis and time to recurrence greater than 5 years $(p=0.05$ and $p=0.02$, respectively) [17], while no relevant differences emerged when considering age and HER 2 status ( $p=0.32$ and $p$ $=0.09$, respectively). However, results in patients with visceral site involvement may now be questionable in light of the results of the FALCON trial, which confirmed a substantial PFS advantage only in patients whose disease had not spread to liver or lungs (22.3 vs 13.8 months, in patients without and with visceral involvement, respectively) [14]. While discussing predictors of treatment outcomes in breast cancer patients undergoing endocrine therapies in the early setting, an interesting suggestion has recently come from a retrospective analysis of data from the transATAC (Arimidex, Tamoxifen Alone or Combined) trial. Results seem to encourage the incorporation of baseline demographic and anthropometric parameters, e.g., age and body mass index (BMI), into molecular scores for the prediction of distant recurrence in HR+HER2- breast cancer patients [18-19].

Given the scant and inconsistent evidence currently available on the potential determinants of treatment outcome in postmenopausal $\mathrm{HR}+$ metastatic breast cancer treated with fulvestrant in $2^{\text {nd }}$ and subsequent line, we designed and conducted an observational study in a historic cohort of patients treated at several Italian cancer centers.

\section{RESULTS}

Overall, the present analysis includes data for 161 patients, whose characteristics are shown in Table 1. In brief, medians and ranges for age, BMI, ER, PgR and Ki-67 percent expression were 68.9 years (35.087.0), 26.0 (16.2-45.3), 90 (1-100), 50 (1-100), and 15 (1-80), respectively. Most of our patients exhibited an ECOG PS equal to 0 [111 (68.9\%)]. The HER2 receptor was overexpressed/amplified in $13(8.1 \%)$ patients and metastatic involvement was revealed at one single site in $78(48.4 \%)$ cases. Bones and viscera were exclusively involved by metastases in $59(31.1 \%)$ and $17(10.6 \%)$ women, respectively, while in the remaining cases (94, $58.3 \%$ ) the metastatic spread followed a mixed pattern. Study participants characteristics across groups defined by endocrine resistance are shown in Table 2. The groups compared significantly differed in terms of BMI $(p=0.02)$, ER percentage expression $(p=0.03)$, HER2 status (0.04), and fulvestrant administration in $1^{\text {st }}$ line or subsequent line of therapy $(p<0.001)$. More specifically, in our cohort, endocrine resistant patients showed more commonly lower BMI, reached more rarely a $30 \%$ cut off for ER expression, were more commonly HER $2+$ and received more frequently fulvestrant in first line compared to endocrine sensitive patients. 
Table 1: Descriptive characteristics of the study participants (N:161).

\section{Median Range}

\begin{tabular}{lcc}
\hline Age (years) & 68.9 & $35.0-87.0$ \\
BMI (kg/m2) & 26 & $16.2-45.3$ \\
\hline ER $^{*}$ & 90 & $1-100$ \\
\hline PgR $^{*}$ & 50 & $1-100$ \\
\hline Ki-67* $^{*}$ & 15 & $1-80$ \\
\hline & $\mathbf{N}$ & $\mathbf{\%}$
\end{tabular}

\section{ECOG PS}

0

1

2

HER2

positive

13

8.1

negative

143

88.80

68.9

23.0

4.3

7

\section{Metastatic sites}

Number

1

2

$\geq 3$

Pattern

Bones

Viscera

Miscellanea
78

65

18

50

17

94

(1)


Table 2: Descriptive characteristics of the study participants by endocrine Resistance/Sensitivity* (N:161).

\begin{tabular}{lccc}
\hline Overall population & $\begin{array}{c}\text { Endocrine-Resistant } \\
\text { Patients } \\
64(39.75)\end{array}$ & $\begin{array}{c}\text { Endocrine-Responsive } \\
\text { Patients } \\
97(36.6)\end{array}$ \\
\hline & $\mathrm{N}(\%)^{\S}$
\end{tabular}

$$
\begin{aligned}
& \text { Age } \\
& <65 \\
& \geq 65
\end{aligned}
$$

ECOG PS

$<25$

$\geq 30$

PgR

negative

positive

HER 2

negative

positive

Ki-67

$<15$

$\geq 15$

Grade

1-2

3

Fulvestrant given in

Ist line

2nd or subsequent

Visceral Involvement
$31(48.4)$

33(51.6)

$49(79.0)$

13(21.0)

$35(54.7)$

29(45.3)

2(3.1)

61(95.3)

$8(12.5)$

$56(87.5)$

$54(84.4)$

$9(14.1)$

$32(33.0)$

$56(57.7)$

11(11.3)

67(69.1)

$58(59.8)$

0.15

0.02

0.03

1.0

11(11.3)

$77(79.4)$

$80(82.5)$

$4(4.1)$

0.04

0.45

23(35.9)

34(35.0)

38(59.4)

43(44.3)

0.76

40(62.5)

55(56.7)

18(28.1)

22(22.7)

$42(65.6)$

22(34.4)
$30(30.9)$

58(59.8)
$<0.0001$

0.27 
$\begin{array}{ll}\text { no } & 32(50.0) \\ \text { yes } & 32(50.0)\end{array}$

Number of metastatic sites

1

$>1$

Bone involvement

No

Yes
$29(45.3)$

$35(54.7)$

43(67.2)

21(32.8)
$52(53.6)$

$36(37.1)$

$47(48.4)$

$41(42.3)$

0.32

0.78

$61(62.8)$

$27(27.8)$

* Patients were considered endocrine resistant if recurrence occurred during or within 12 months after the end of adjuvant treatment or progression was recorded while on or within 1 month after the completion of treatment for advanced disease. $\S$ Percentages may not add up to 100 because of missing values

BMI: body mass index, ER and/or PgR: estrogen and/or progesterone receptor; ER: estrogen receptor; PgR: progesterone receptor.

None of the variables tested had a significant impact on OR, neither in endocrine sensitive nor in endocrine resistant patients (data available upon request). Conversely, within the subgroup of endocrine sensitive patients, Clinical benefit rate (CBR) was affected by percent expression of ER and line of therapy, with the highest rates being recorded in patients with a ER percentage expression of at least 30 and having received fulvestrant in $1^{\text {st }}$ line ( $p=0.02$ and 0.046 , respectively) (data available upon request).

Results from univariate analyses addressing the role of anthropometric, clinical and molecular factors on survival across strata defined upon endocrine sensitivity/ resistance are shown in Table 3.

In the endocrine resistant subgroup, PFS was significantly longer for patients in the lowest category of BMI ( $p=0.01)$, while, among endocrine sensitive women, longer PFS was observed in cases treated with fulvestrant in $1^{\text {st }}$ line $(p=0.01)$, with metastatic involvement limited to one single site $(p=0.01)$ and with no extension to visceral sites $(p=0.003)$. Among endocrine resistant patients, HER2 positive status was associated with poorer OS $(p=0.03)$, similarly to having received fulvestrant in $2^{\text {nd }}$ and subsequent lines $(p=0.03)$. In endocrine sensitive patients, we observed worse outcome in case of multiple metastatic sites $(p=0.008)$. In multivariate analysis (Table

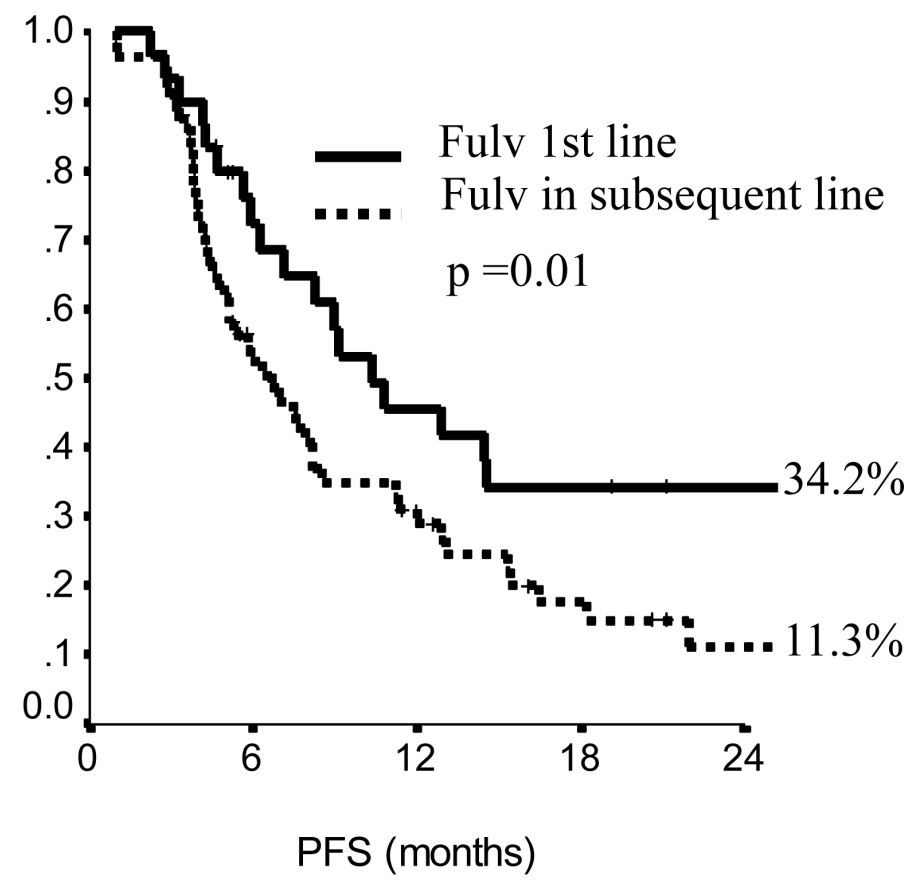

Figure 1: Progression free survival (PFS) in endocrine sensitive patients. The impact of line of therapy (fulvestrant in first versus subsequent line). 
Table 3: Univariate analysis of the impact of anthropometric, molecular and metabolic determinants on survival in endocrine sensitive (N:97) and endocrine resistant (N:64) patients HR+ metastatic breast cancer patients treated with fulvestrant.

\begin{tabular}{|c|c|c|c|c|c|c|c|c|}
\hline \multirow[t]{3}{*}{ Variables } & \multicolumn{4}{|c|}{ Median ${ }^{1}$ PFS $\left(95 \%{ }^{3} \mathrm{Cl}\right)$} & \multicolumn{4}{|c|}{ Median ${ }^{2}$ OS $(95 \% \mathrm{Cl})$} \\
\hline & \multicolumn{4}{|c|}{ Endocrine Sensitivity } & \multicolumn{4}{|c|}{ Endocrine Sensitivity } \\
\hline & $\begin{array}{l}\text { No } \\
N: 64\end{array}$ & $\mathrm{p}$ & $\begin{array}{l}\text { Yes } \\
\text { N: } 97\end{array}$ & $\mathrm{p}$ & $\begin{array}{l}\text { No } \\
\text { N: } 64\end{array}$ & $\mathrm{p}$ & $\begin{array}{l}\text { Yes } \\
\text { N: } 97\end{array}$ & $\mathrm{p}$ \\
\hline \multicolumn{9}{|l|}{${ }^{4} \mathrm{BMI}$} \\
\hline$<25$ & $7(6-7)$ & 0.01 & $7(5-9)$ & 0.10 & $35(15-55)$ & 0.36 & $23(2-44)$ & 0.05 \\
\hline$>=25$ & $5(4-7)$ & & $8(4-12)$ & & $22(16-27)$ & & $52(26-78)$ & \\
\hline \multicolumn{9}{|l|}{${ }^{5}$ HER2 } \\
\hline Pos & $6(5-7)$ & 0.87 & $6(0-17)$ & 0.60 & $12(7-17)$ & 0.03 & n.r. & 0.32 \\
\hline Neg & $5(3-6)$ & & $8(6-9)$ & & $30(19-42)$ & & $40(20-61)$ & \\
\hline \multicolumn{9}{|l|}{ Age } \\
\hline$>=65$ & $6(4-7)$ & 0.40 & $8(7-10)$ & 0.05 & $24(12-35)$ & 0.97 & n.a. & 0.09 \\
\hline $\begin{array}{l}<65 \\
{ }^{6} \mathrm{ER} \%\end{array}$ & $6(5-7)$ & & $6(3-8)$ & & $25(9-41)$ & & $52(8-95)$ & \\
\hline$>=30$ & $6(5-7)$ & n.a. & $8(6-9)$ & 0.86 & $24(13-34)$ & & $40(25-55)$ & 0.24 \\
\hline$<30$ & n.a. & & $4(3-5)$ & & n.a. & & n.a. & \\
\hline \multicolumn{9}{|l|}{${ }^{7} \mathrm{PgR}$} \\
\hline Neg & $6(0-13)$ & 0.77 & n.a. & 0.15 & n.a. & 0.68 & n.a. & 0.28 \\
\hline Pos & $6(5-8)$ & & $8(6-9)$ & & $24(12-35)$ & & $41(23-59)$ & \\
\hline \multicolumn{9}{|l|}{ Ki67\% } \\
\hline$<15$ & 6 mesi (4-9) & 0.73 & $7(5-8)$ & 0.074 & $21(17-26)$ & 0.41 & $41(19-63)$ & 0.93 \\
\hline$>=15$ & 6 mesi (4-7) & & $11(3-18)$ & & $30(17-44)$ & & n.a. & \\
\hline \multicolumn{9}{|c|}{$\begin{array}{l}\text { Fulvestrant in } \\
\text { 1st/subsequent }\end{array}$} \\
\hline line: & $7(5-8)$ & 0.09 & $10(6-15)$ & 0.01 & $32(19-44)$ & 0.03 & n.r. & 0.17 \\
\hline 1 & $5(4-6)$ & & $7(4-9)$ & & $19(9-29)$ & & $29(8-50)$ & \\
\hline \multicolumn{9}{|c|}{$\geq 2$} \\
\hline \multicolumn{9}{|c|}{$\begin{array}{l}\mathrm{N} \text { metastatic } \\
\text { sites }\end{array}$} \\
\hline 1 & $6(5-7)$ & 0.85 & $10(2-18)$ & 0.003 & $35(22-49)$ & 0.11 & n.a. & 0.008 \\
\hline$>1$ & $5(4-6)$ & & $7(4-10)$ & & $22(10-33)$ & & $25(16-34)$ & \\
\hline \multicolumn{9}{|c|}{$\begin{array}{l}\text { Visceral } \\
\text { Involvement }\end{array}$} \\
\hline Yes & $6(5-8)$ & 0.69 & $6(2-10)$ & 0.01 & $32(22-42)$ & 0.19 & $40(12-68)$ & 0.09 \\
\hline No & $5(3-7)$ & & $9(3-15)$ & & $19(8-30)$ & & n.a. & \\
\hline
\end{tabular}

4), for endocrine resistant patients, lower BMI and older age appeared associated with lower risk of progression ( $p=0.02$ and 0.007 , respectively), while in endocrine sensitive patients we observed some evidence suggesting longer PFS in women who were older at diagnosis and had only one site involved by metastatic spread ( $p=0.06$ for both). When addressing OS, in endocrine resistant patients, HER 2 positivity conferred a more than two-fold risk, along with fulvestrant administration in second and subsequent line of therapy ( $p=0.04$ for both). In endocrine sensitive women, the involvement of multiple metastatic sites was strongly associated with worse outcome ( $p=$ 0.002).

\section{DISCUSSION}

Within the study herein presented, we analyzed data of 161 postmenopausal HR+ metastatic breast cancer patients treated with fulvestrant in $1^{\text {st }}$ and subsequent line of therapy following development of resistance to 
Table 4: Multivariate analysis of the impact of anthropometric, molecular and metabolic determinants on survival in endocrine sensitive (N:97) and endocrine resistant $(\mathrm{N}: 64)$ patients HR+ metastatic breast cancer patients treated with fulvestrant

\begin{tabular}{|c|c|c|c|c|c|c|c|c|}
\hline \multirow[t]{3}{*}{ Variables } & \multicolumn{4}{|c|}{ HR $(95 \% \mathrm{Cl})$ PFS } & \multicolumn{4}{|c|}{ HR OS $(95 \% \mathrm{Cl})$} \\
\hline & \multicolumn{3}{|c|}{ Endocrine Sensitivity } & \multicolumn{5}{|c|}{ Endocrine Sensitivity } \\
\hline & $\begin{array}{c}\text { No } \\
\text { N: } 64\end{array}$ & $P$ & $\begin{array}{l}\text { Yes } \\
\text { N:97 }\end{array}$ & $p$ & $\begin{array}{c}\text { No } \\
\text { N: } 64\end{array}$ & $\mathrm{p}$ & $\begin{array}{c}\text { Yes } \\
\mathrm{N}: 97\end{array}$ & $p$ \\
\hline $\begin{array}{l}\text { BMI } \\
>=25 \text { vs }<25\end{array}$ & $1.89(1.11-3.24)$ & 0.02 & - & - & - & - & $1.89(0.94-3.82)$ & 0.08 \\
\hline $\begin{array}{l}\text { HER2 } \\
\text { Pos vs Neg }\end{array}$ & - & - & - & - & $2.48(1.04-5.91)$ & 0.04 & - & - \\
\hline Age & $0.97(0.94-0.99)$ & 0.007 & $0.98(0.95-1.0)$ & 0.06 & - & - & - & - \\
\hline $\begin{array}{l}\text { Fulvestrant in } \\
\text { subsequent line } \\
\text { vs 1st }\end{array}$ & - & - & $1.89(1.08-3.31)$ & 0.03 & $2.13(1.04-4.33)$ & 0.04 & - & - \\
\hline $\begin{array}{l}\text { N metastatic } \\
\text { sites } \\
>1 \text { vs } 1\end{array}$ & - & - & $1.69(0.97-2.93)$ & 0.06 & - & - & $3.32(1.56-7.13)$ & $\begin{array}{c}0.00 \\
2\end{array}$ \\
\hline $\begin{array}{l}\text { Visceral } \\
\text { involvement } \\
\text { Yes vs No }\end{array}$ & - & - & $1.58(0.92-2.72)$ & .10 & - & - & - & - \\
\hline
\end{tabular}

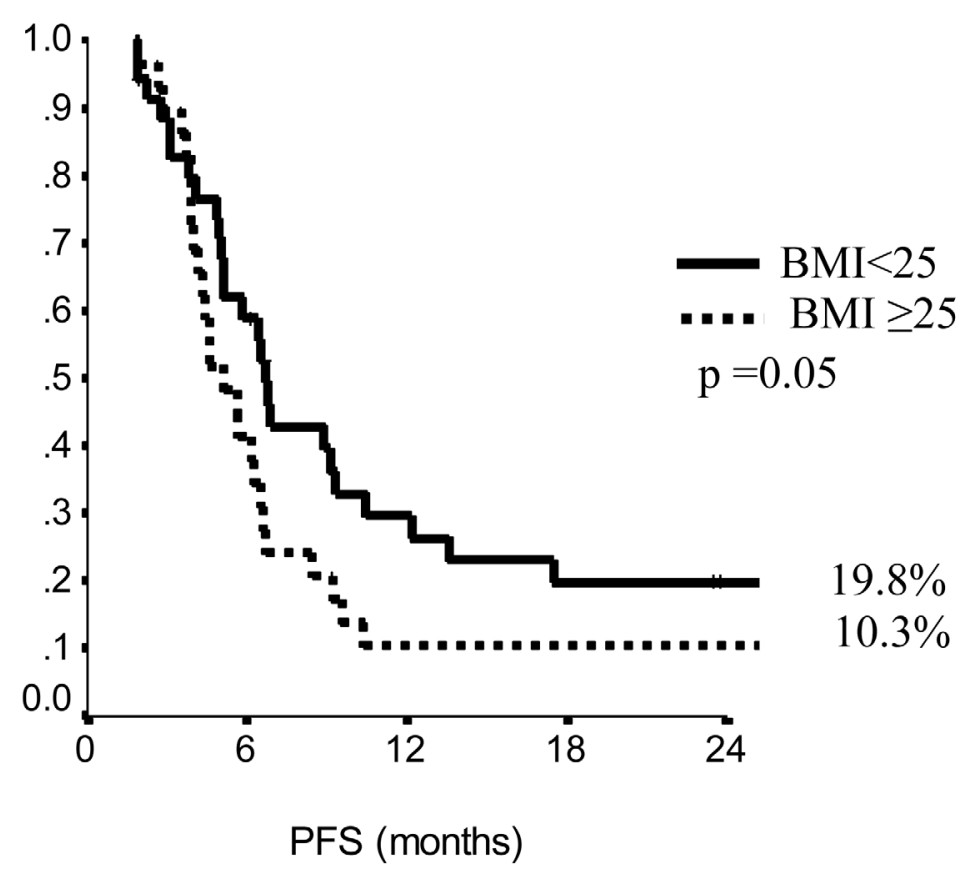

Figure 2: Progression free survival in endocrine resistant patients. 
AI. Based on the outcome related to this latter treatment, patients were defined as endocrine sensitive or resistant. The overall analytical approach was thus based on the stratification by response to prior endocrine therapy. This allowed to highlight how distinct determinants may affect treatment efficacy within these two groups of postmenopausal $\mathrm{HR}+$ metastatic breast cancer patients treated with fulvestrant. In brief, CBR was more commonly achieved in endocrine sensitive patients with higher ER percent expression and in those who received fulvestrant in $1^{\text {st }}$ line, while no specific determinants seemed to affect CBR at a significant extent in endocrine resistant patients. Progression free survival appeared to be positively influenced by lower BMI in endocrine resistant patients, whereas treatment administration in $1^{\text {st }}$ line, one single metastatic site and no visceral involvement were associated with sensibly longer PFS in endocrine sensitive patients. Univariate analysis of OS tested significant for HER2 status and line of treatment in endocrine resistant patients, who were disfavored in case HER2 positivity and $2^{\text {nd }}$ or subsequent line fulvestrant, while endocrine sensitive patients showed worse outcomes in case of multiple metastatic involvement. As expected, multivariate models confirmed a restricted number of factors. More specifically, PSF resulted longer in resistant patients who were older at diagnosis and showed lower BMI, while, in endocrine sensitive patients there was some evidence in support of more favorable outcomes related with older age and single metastatic site involvement. Overall survival was shorter in endocrine resistant patients expressing
HER2 and having been treated with fulvestrant in $2^{\text {nd }}$ and subsequent lines. In endocrine sensitive patients, worse OS was associated with multiple metastatic site involvement.

The analytic approach used by our group represents a shortcut to the immediate use of data from the real world population setting in orienting towards the most suitable therapeutic approach at the single patient level based on the outcome of prior exposure to endocrine therapy. Such a feasible approach is not meant to be exhaustive in providing all the key elements required for the most appropriate therapeutic choice within the rapidly expanding armamentarium of endocrine agents, but to add informative pieces to the overall puzzle based on promptly available patient- and disease-related info. This may result particularly attractive in light of some criticisms emerging from the a rapid overview of the most recent literature on fulvestrant in $\mathrm{HR}+$ locally advanced and metastatic breast cancer. As previously mentioned, the FALCON trial was carried out in endocrine naïve patients [14]. This has made its results fairly comparable to those from the FIRST trial, whose participants had be mostly not exposed to endocrine therapy prior to study entry. Results from both these studies have undoubtedly concurred to provide evidence concerning superior efficacy of fulvestrant over $3^{\text {rd }}$ generation aromatase inhibitors. Yet, given the characteristics of the overall population enrolled in the phase III study and in the FIRST trial, this evidence is barely generalizable to patients from the real world setting and, as such, not comparable to our study results. When looking beyond recent literature

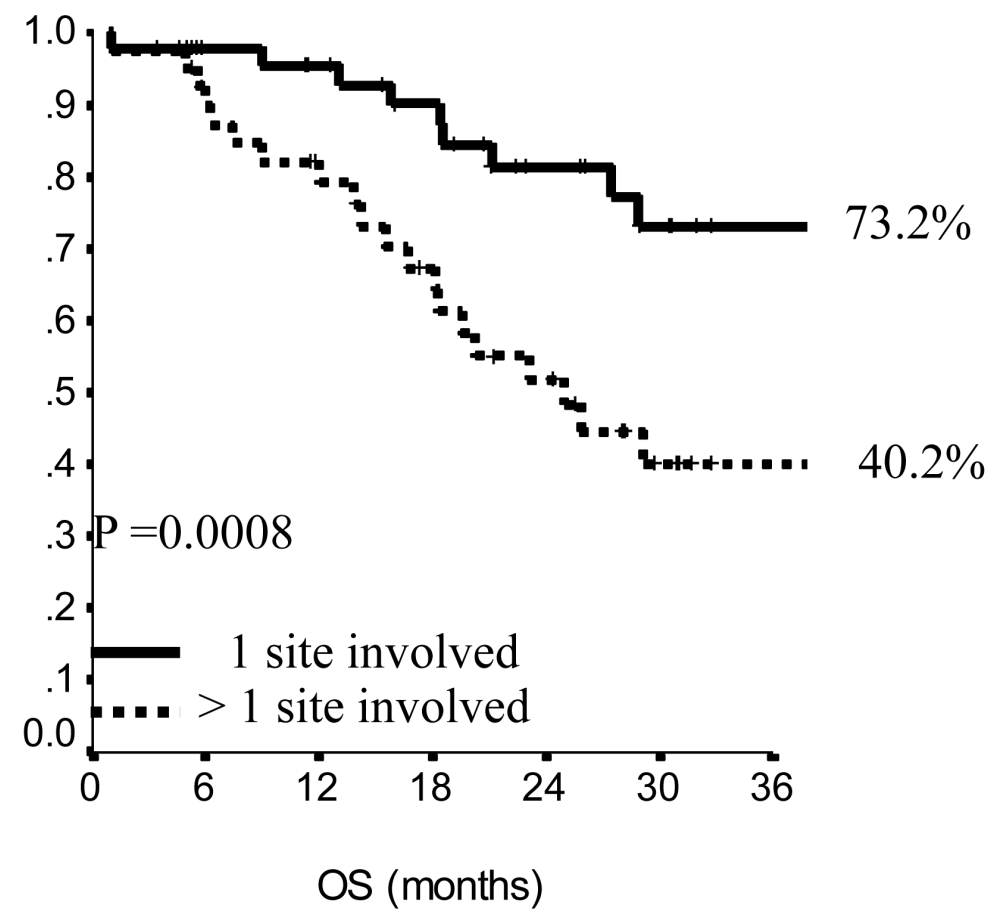

Figure 3: Overall survival in endocrine sensitive patients. 
from randomized clinical trials, fulvestrant use in $\mathrm{HR}+$ advanced breast cancer has been addressed by Gevorgyan and colleagues, who examined the role of BMI on CBR in a retrospective study of seventy-five consecutive patients treated with fulvestrant at a single institution. The authors observed better outcomes in normal-weight patients compared with underweight and overweight/ obese patients (CBR: 70.0, 31.6 and $25.0 \%$, respectively, $p<0.001$ ) [20]. In our study population, we observed no effects of BMI on CBR. However, our results support a role of BMI on PFS, with longer PFS being observed in endocrine resistant patients with lower BMI values. This

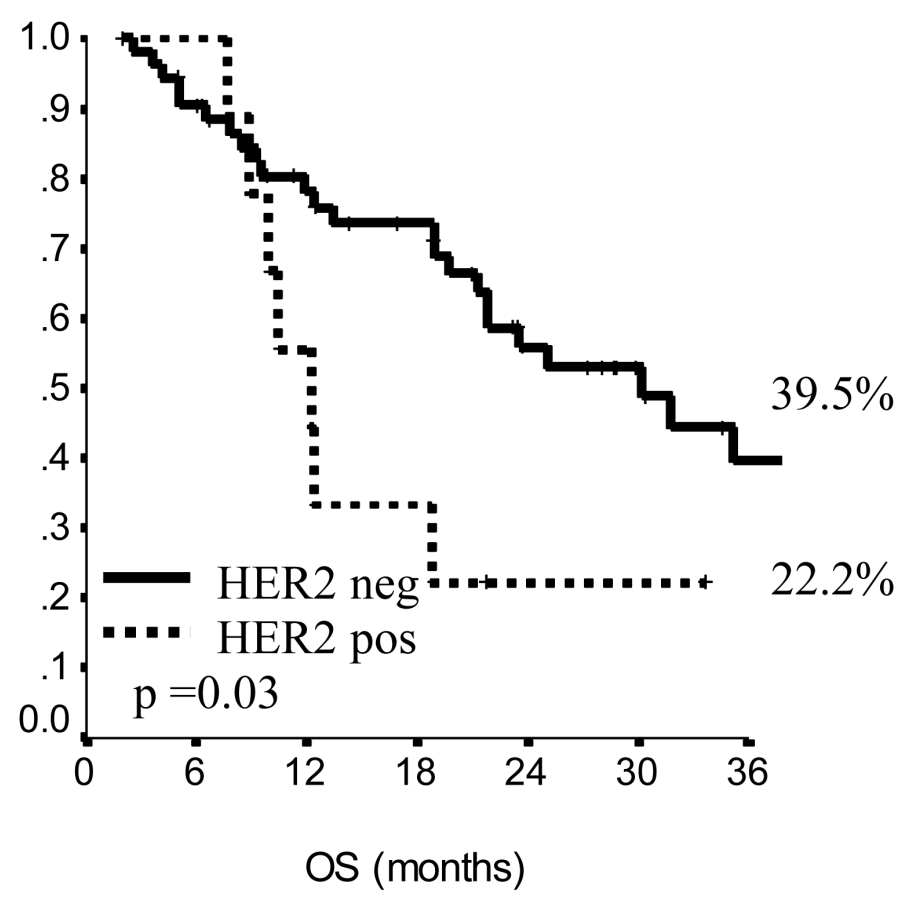

Figure 4: Overall survival in endocrine sensitive patients.

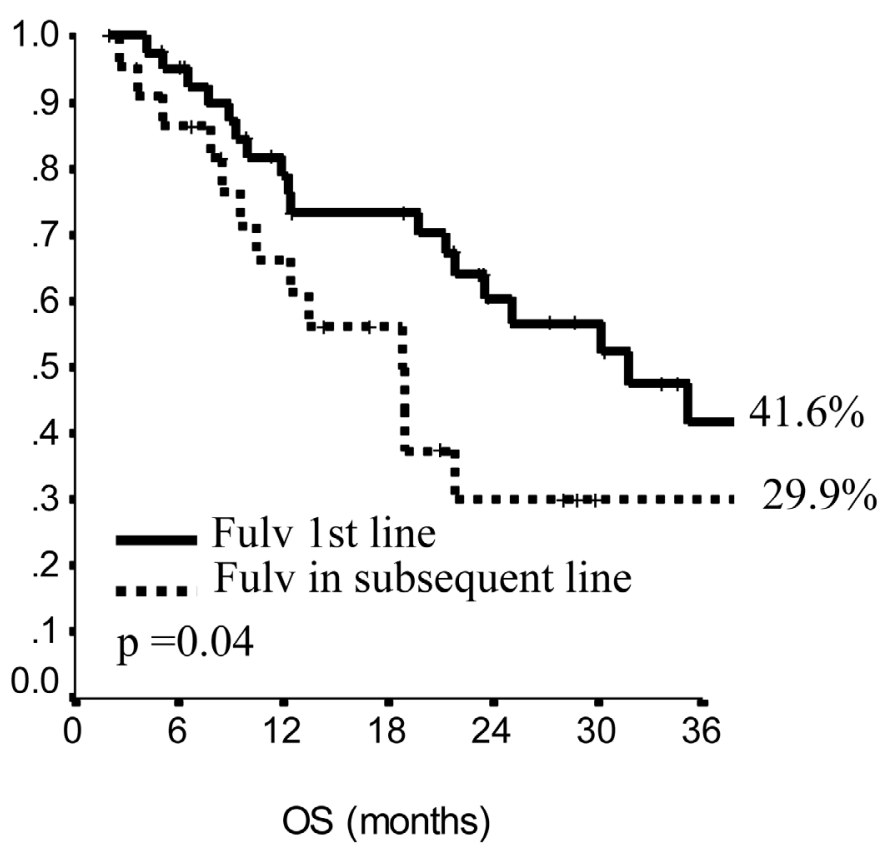

Figure 5: Overall survival in endocrine sensitive patients. 
latter evidence surely represents the most intriguing result from our analysis. Indeed, with the lonely exception of the study from Gevorgyan and colleagues [20], no other study has previously addressed the predictive role of BMI on treatment outcome in breast cancer patients treated with fulvestrant. More generally, there is paucity of data concerning the influence of BMI on endocrine therapy outcome in the advanced setting. According to the results reported by Michaud et al., BMI had no predictive value on TTP and response rates in metastatic breast cancer patients treated with anastrozole compared with tamoxifen. Similar conclusions were drawn by Schmid and coauthors when analyzing data from patients treated with letrozole or megestrol acetate [21-23]. Conversely, evidence from our study seems to encourage the use of fulvestrant in patients with lower BMI who showed prior hormone resistance. Within the limits imposed by the relatively restricted sample size and observational nature of our study, we may speculate that both estrogen- and non-estrogen dependant mechanisms may concur to explain the outcome observed. In patients with higher BMI, a greater volume of adipose tissue may be associated with an overall increased aromatase activity. It is also plausible that in obese and overweight patients higher insulin levels may activate fetal insulin/IGF-1 receptors on breast cancer cells and activate cell signaling through PI3K and Ras-Raf pathways. In addition, the cross-talk between IGF-1/insulin signaling pathways and estrogenic signaling pathways is well documented. Thus, enhanced signaling mediated by the insulin IGF-1 pathway in overweight and obese patients may activate estrogen signaling pathways [24-26].

To our knowledge, no further evidence potentially useful to inform decisions on fulvestrant use in advanced breast cancer has recently come from the clinical setting. Less recent work has been carried out by Knudsen and colleagues on the development and validation of a gene expression score to predict response to fulvestrant in the neoadjuvant setting. The potential predictor was applied to tissue specimen sampled before neoadjuvant fulvestrant in patients from a phase II trial. The inclusion of clinical covariate, tumor grade and ER expression increased the difference in sensitivity between responders and not responders $(p=0.003)$ [27]. Beyond its limitations, punctually addressed by the authors in the discussion, results from this study seem to be particularly encouraging concerning the combined use of new-fashion techniques and old-fashion approaches, i.e., gene signatures coupled with tumor- and patient-features possibly including $\mathrm{BMI}$, in the decision making process eventually leading to fulvestrant administration. This strategy may result effective across different breast cancer setting, In specific regard to the advanced setting for postmenopausal HR+HER2-breast cancer, such an approach may result of particular interest in re-defining the therapeutic continuum for candidates to endocrine therapy following the FDA approval of the cycline dependent inhibitor palbociclib in combination with endocrine agent [28].

Our study has some limitations, mostly related to its design and placement within the real world clinical setting. Clinical series are by nature prone to confounding and bias, which should always invite caution in results' interpretation. Missing values for the variables of interest were highlighted when presenting results in the pertinent tables. Unfortunately, systematic data collection and update in course of follow up have not stably entered the clinical practice settings yet, and the related processes are still amenable to implementation. The multicentric design has greatly improved our enrollment abilities, but no central assessment has been performed on the samples from included participants. However, the dedicated labs at the enrolling institutions are constantly involved in quality controls and ISO 9001-certied.

Our study also have strengths of relevance. In first place, our study provides evidence in support of differentials patient- and disease-related characteristics related to response to prior exposure to endocrine therapy. At the same time, this may add in terms of interpretations of the outcomes from a previous treatment and inform future decisions within an increasingly articulated therapeutic strategy which is not limited to the immediately upcoming therapeutic choice. This may translate into a more appropriate short- and mid-term therapeutic planning for our patients. In addition, data from a non selected population, which does not satisfy strict inclusion and exclusion criteria to allow inclusion in randomized clinical trial, are more easily adaptable to the needs of both real world patients and actively practicing oncologists.

In brief, we carried out an analysis of data from 161 postmenopausal HR + metastatic breast cancer patients who had received fulvestrant in $1^{\text {st }}$ and subsequent line of therapy following development of resistance to AI. Stratification by endocrine sensitivity/resistance helped identify factors significantly differing across the groups compared. Among such differential traits, several determinants had a relevant impact on patients' important outcomes. Pending our results' confirmation in future studies, such an approach may be efficiently integrated by the results of genomics and transcriptomics techniques to more appropriately inform fulvestrant use, and, more generally, therapeutic decisions in $\mathrm{HR}+$ metastatic breast cancer.

\section{MATERIALS AND METHODS}

The analysis herein proposed includes data from a larger study of postmenopausal HR + metastatic breast cancer patients who had developed resistance following endocrine therapy with AI. Details on methods have been extensively provided elsewhere [29]. In brief, in this cohort, women were categorized based on their response 
in terms of resistance/responsiveness to prior endocrine therapy. In more details, patients previously exposed to endocrine therapy in the adjuvant setting were judged "hormone resistant" if their disease recurred while on treatment or within 12 months after the end of adjuvant therapy. Similarly, those patients who had received prior endocrine therapy in the advanced setting were considered "hormone resistant" if disease progression occurred while on treatment or within 1 month after the completion of therapy. Prior chemotherapy regimens and anticancer endocrine therapies for advanced disease were allowed. An Eastern Cooperative Oncology Group (ECOG) performance status (PS) of 2 or less and adequate organ and hematologic functions were requested. Asymptomatic CNS metastases were not an exclusion criterion. Surgery or radiation therapy of brain lesions was admitted if performed within 3 months preceding study entry. Bisphosphonate treatment was allowed. Fulvestrant was administered according to the current indications and recommendations [15-16].

Five Italian cancer centers contributed data to the present analysis. An ad hoc database was conceived and implemented for data collection. Data of interest were pertinent to patient demographics, anthropometrics (weight, eight, BMI), clinical and morphological features, treatment/s administered and related outcomes. When considering ER percent expression in both descriptive and inferential statistics, we set up two different cut off levels, i.e., 30 and $50 \%$. The related categorical variables were both tested, with results being reported according to the most conservative choice, i.e., a cut off value of $30 \%$, unless the two cut off values generated significantly differences. To the purpose of our analysis, BMI was computed as weight in kilograms divided by the square of the height in meters and addressed as a categorical variable using a 25 cut off value. Among the outcomes of interest, objective response (OR) was codified according to conventional Response Evaluation Criteria in Solid Tumours (RECIST) version 1.1. Clinical benefit rate CBR was addressed as the percentage of patients with shrinking tumors or stable disease for at least 6 months. Progression free survival was defined as the time elapsed between treatment start and interruption due to disease progression or death from any cause. Overall survival was defined as the time from the start of treatment to patient death from any cause. The study was conducted in accordance with Helsinki Declaration and approved by Independent Ethical Committees of the institutes involved. All the patients provided their written informed consent.

\section{Statistical analysis}

Descriptive characteristics were first approached for the overall study population and for all the variables of interest. Medians and ranges were computed for continuous variables, while frequencies and percentages were used for categorical variables. Patients' characteristics were then compared across groups defined upon endocrine resistance in full accordance with the above reported definition using $\mathrm{X}^{2} /$ Fisher test. Any statistically relevant difference emerging from this latter comparison was further considered in analyses testing the impact of anthropometric, clinical and molecular features on treatment outcomes. The Hazard Ratio and confidence limits (CI) were estimated for each variable using the Cox univariate model. Significance was defined at the $p \leq 0.05$ level. A multivariate Cox hazard model was developed using stepwise regression (forward selection) by selecting significant variables upon univariate analysis. Enter limit and remove limit were $p=0.05$ and $p=0.10$, respectively. Survival curves were calculated by the Kaplan-Meier method and the log-rank test was used to assess differences between subgroups. Significance was defined at the $p \leq 0.05$ level. Statistical analyses were performed with SPSS statistical software version 20 (SPSS inc., Chicago IL, USA).

\section{ACKNOWLEDGMENTS}

We thank Mrs Ana Maria Edlisca for technical assistance. We are also grateful to the C.I.N.B.O. (Consorzio Inter-universitario Nazionale per la BioOncologia) for administrative support.

\section{CONFLICTS OF INTEREST}

Laura Pizzuti declares that she has no conflict of interest. Clara Natoli declares that she has no conflict of interest. Teresa Gamucci declares she has no conflict of interest. Mariella Mauri declares she has conflict of interest. Domenico Sergi declares he has not no conflict of interest. Luigi Di Lauro declares he has no conflict of interest conflict of interest. Giancarlo Paoletti declares he no conflict of interest. Enzo Ruggeri declares he has no conflict of interest. Laura Iezzi declares she has no conflict of interest. Isabella Sperduti declares she has no conflict of interest. Lucia Mentuccia declares she has no conflict of interest. Agnese Fabbri declares she has no conflict of interest. Marcello Maugeri-Saccà declares he has no conflict of interest. Luca Moscetti declares he has no conflict of interest. Maddalena Barba declares she has no conflict of interest. Patrizia Vici declares she has no conflict of interest.

\section{FUNDING}

Not Applicable. This study represents spontaneous work from the institutions involved. 


\section{ETHICAL APPROVAL}

All procedures performed in studies involving human participants were in accordance with the ethical standards of the institutional and/or national research committee and with the 1964 Helsinki declaration and its later amendments or comparable ethical standards.

\section{REFERENCES}

1. Rugo HS, Rumble RB, Macrae E, Barton DL, Connolly HK, Dickler MN, Fallowfield L, Fowble B, Ingle JN, Jahanzeb M, Johnston SR, Korde LA, Khatcheressian JL, et al. Endocrine Therapy for Hormone Receptor-Positive Metastatic Breast Cancer: American Society of Clinical Oncology Guideline. J Clin Oncol. 2016; 34:3069-103. doi: 0.1200/JCO.2016.67.1487.

2. Carlson RW. The history and mechanism of action of fulvestrant. Clin Breast Cancer. 2005; 6:S5-8.

3. Poggio F, Lambertini M, Blondeaux E, Vaglica M, Levaggi A, Pronzato P, Del Mastro L. Role of fulvestrant in the treatment of postmenopausal metastatic breast cancer patients. Expert Rev Clin Pharmacol. 2016; 9:153-61. doi: 10.1080/17512433.2016.1215243.

4. Howell A, Robertson JF, Quaresma Albano J, Aschermannova A, Mauriac L, Kleeberg UR, Vergote I, Erikstein B, Webster A, Morris C. Fulvestrant, formerly ICI 182,780 , is as effective as anastrozole in postmenopausal women with advanced breast cancer progressing after prior endocrine treatment. J Clin Oncol. 2002; 20:3396-403. doi:10.1200/JCO.2002.10.057.

5. Osborne CK, Pippen J, Jones SE, Parker LM, Ellis M, Come S, Gertler SZ, May JT, Burton G, Dimery I, Webster A, Morris C, Elledge R, Buzdar A. Double-blind, randomized trial comparing the efficacy and tolerability of fulvestrant versus anastrozole in postmenopausal women with advanced breast cancer progressing on prior endocrine therapy: Results of a North American trial. J Clin Oncol. 2002; 20:3386-95.

6. Robertson JF, Osborne CK, Howell A, Jones SE, Mauriac L, Ellis M, Kleeberg UR, Come SE, Vergote I, Gertler S, Buzdar A, Webster A, Morris C. Fulvestrant versus anastrozole for the treatment of advanced breast carcinoma in postmenopausal women: A prospective combined analysis of two multicenter trials. Cancer. 2003; 98:229-38. doi:10.1002/cncr.11468.

7. Robertson JF, Nicholson RI, Bundred NJ, Anderson E, Rayter Z, Dowsett M, Fox JN, Gee JM, Webster A, Wakeling AE, Morris C, Dixon M. Comparison of the short-term biological effects of 7alpha-[9-(4,4,5,5,5pentafluoropentylsulfinyl)nonyl] estra-1,3,5, (10)-triene-3, 17beta-diol (Faslodex) versus tamoxifen in postmenopausal women with primary breast cancer. Cancer Res. 2001; 61:6739-46.

8. DeFriend DJ, Howell A, Nicholson RI, Anderson E,
Dowsett M, Mansel RE, Blamey RW, Bundred NJ, Robertson JF, Saunders C, Baum M, Walton P, Sutcliffe F, Wakeling AE. Investigation of a new pure antiestrogen $(1 \mathrm{Cl}$ 182780 ) in women with primary breast cancer. Cancer Res. 1994; 54:408-14.

9. Kuter I, Gee JM, Hegg R, Singer CF, Badwe RA, Lowe ES, Emeribe UA, Anderson E, Sapunar F, Finlay P, Nicholson RI, Bines J, Harbeck N. Dose-dependent change in biomarkers during neoadjuvant endocrine therapy with fulvestrant: results from NEWEST, a randomized Phase II study. Breast Cancer Res Treat. 2012; 133:237-46. doi: 10.1007/s10549-011-1947-7.

10. Di Leo A, Jerusalem G, Petruzelka L, Torres R, Bondarenko IN, Khasanov R, Verhoeven D, Pedrini JL, Smirnova I, Lichinitser MR, Pendergrass K, Garnett S, Lindemann JP, et al. Results of the CONFIRM phase III trial comparing fulvestrant $250 \mathrm{mg}$ with fulvestrant $500 \mathrm{mg}$ in postmenopausal women with estrogen receptor-positive advanced breast cancer. J Clin Oncol. 2010; 28:4594-600.

11. Di Leo A, Jerusalem G, Petruzelka L, Torres R, Bondarenko IN, Khasanov R, Verhoeven D, Pedrini JL, Smirnova I, Lichinitser MR, Pendergrass K, Malorni L, Garnett S, et al. Final overall survival: fulvestrant $500 \mathrm{mg}$ vs $250 \mathrm{mg}$ in the randomized CONFIRM trial. J Natl Cancer Inst. 2014; 106:djt337. doi:10.1093/jnci/djt337.

12. Robertson JF, Llombart-Cussac A, Rolski J, Feltl D, Dewar J, Macpherson E, Lindemann J, Ellis MJ. Activity of fulvestrant $500 \mathrm{mg}$ versus anastrozole $1 \mathrm{mg}$ as first-line treatment for advanced breast cancer: Results from the FIRST study. J Clin Oncol. 2009; 27:4530-5. doi:10.1200/ JCO.2008.21.1136.

13. Ellis MJ, Llombart-Cussac A, Feltl D, Dewar JA, Jasiówka M, Hewson N, Rukazenkov Y, Robertson JF. Fulvestrant $500 \mathrm{mg}$ Versus Anastrozole $1 \mathrm{mg}$ for the First-Line Treatment of Advanced Breast Cancer: Overall Survival Analysis From the Phase II FIRST Study. J Clin Oncol. 2015; 10:3781-7. doi:10.1200/JCO.2015.61.5831.

14. Robertson JF, Bondarenko IM, Trishkina E, Dvorkin M, Panasci L, Manikhas A, Shparyk Y, Cardona-Huerta S, Cheung KL, Philco-Salas MJ, Ruiz-Borrego M, Shao Z, Noguchi S, et al. Fulvestrant $500 \mathrm{mg}$ versus anastrozole 1 mg for hormone receptor-positive advanced breast cancer (FALCON): an international, randomised, double-blind, phase 3 trial. Lancet. 2016; 388: 2997-3005. doi:10.1016/ S0140-6736(16)32389-3.

15. http://www.accessdata.fda.gov/drugsatfda_docs/applett er/2012/021344Orig1s019,s0201tr.pdf (last accessed in November 2016).

16. http://www.ema.europa.eu/ema/index.jsp?curl=pages/ medicines/human/medicines/000540/human_med_000786. jsp\&mid=WC0b01ac058001d124(last accessed in November 2016).

17. Graham J, Pitz M, Gordon V, Grenier D, Amir E, Niraula S. Clinical predictors of benefit from fulvestrant in advanced breast cancer: A Meta-analysis of randomized controlled 
trials. Cancer Treat Rev. 2016; 45:1-6. doi:10.1016/j. ctrv.2016.02.004.

18. Sestak I, Dowsett M, Ferree S, Baehner FL, Cuzick J. Retrospective analysis of molecular scores for the prediction of distant recurrence according to baseline risk factors. Breast Cancer Res Treat. 2016; 159:71-8. doi:10.1007/ s10549-016-3868-y.

19. Dowsett M, Cuzick J, Wale C, Forbes J, Mallon EA, Salter J, Quinn E, Dunbier A, Baum M, Buzdar A, Howell A, Bugarini R, Baehner FL, Shak S. Prediction of risk of distant recurrence using the 21-gene recurrence score in node-negative and node-positive postmenopausal patients with breast cancer treated with anastrozole or tamoxifen: a TransATAC study. J Clin Oncol. 2010; 8:1829-34. doi: 10.1200/JCO.2009.24.4798.

20. Gevorgyan A, Bregni G, Galli G, Ganzinelli M, Martinetti A, Lo Vullo S, Mariani L, Festinese F, Sottotetti E, de Braud F, Di Cosimo S. Body mass index and clinical benefit of fulvestrant in postmenopausal women with advanced breast cancer. Tumori. 2016; 102:e11-e14. doi:10.5301/tj.5000515.

21. Michaud LB, Buzdar AU, Rubin S, Steinberg M, Yin H, Aaronson L, Nabholtz JM. The efficacy of anastrozole is not dependent upon body mass index in postmenopausal women with advanced breast cancer. Proc Am Soc Clin Oncol. 2002; 21: abstr 219.

22. Schmid P, Possinger K, Bohm R, Chaudri V, Verbeek V, Grosse Y,Chaudri V, Verbeek V. Body mass index as predictive parameter for response and time to progression in advanced breast cancer patients treated with letrozole or megestrol acetate. Proc Am Soc Clin Oncol. 2000; 19: abstr 398.
23. Goodwin PJ. Obesity and endocrine therapy: host factors and breast cancer outcome. Breast. 2013; Suppl 2:S44-7. doi: 10.1016/j.breast.2013.07.008.

24. Geisler J, Haynes B, Ekse D, Dowsett M, Lønning PE. Total body aromatization in postmenopausal breast cancer patients is strongly correlated to plasma leptin levels. J Steroid Biochem Mol Biol. 2007;104:27-34.

25. Goodwin PJ, Ennis M, Pritchard KI, Trudeau ME, Koo J, Madarnas Y, Hartwick W, Hoffman B, Hood N. Fasting insulin and outcome in early-stage breast cancer: results of a prospective cohort study. J Clin Oncol. 2002; 20:42-51.

26. Fagan DH, Yee D. Crosstalk between IGF1R and estrogen receptor signaling in breast cancer. J Mammary Gland Biol Neoplasia. 2008;13:423-9. doi: 10.1007/s10911-008-90980 .

27. Kundsen S, Jensen T, Hansen A, Mazin W, Lindemann J, Kuter I, Laing N, Anderson E. Development and validation of a gene expression score that predicts response to fulvestrant in breast cancer patients. PLOS ONE. 2014; 9:e87415.

28. http:/www.fda.gov/Drugs/InformationOnDrugs/ ApprovedDrugs/ucm487080.htm. Last accessed in February 2017.

29. Moscetti L, Vici P, Gamucci T, Natoli C, Cortesi E, Marchetti P, Santini D, Giuliani R, Sperduti I, Mauri M, Pizzuti L, Mancini ML, Fabbri MA, et al.. Safety analysis, association with response and previous treatments of everolimus and exemestane in 181 metastatic breast cancer patients: A multicenter Italian experience. Breast. 2016; 29:96-101. doi:10.1016/j.breast.2016.07.005. 